\title{
Theoretical modeling and optimization of microchannel heat sink cooling with $\mathrm{TiO}_{2}$-water and ZnO-water nanofluids
}

\author{
Sayantan Mukherjee ${ }^{1}$, Purna C. Mishra ${ }^{1}$, Paritosh Chaudhuri ${ }^{2}$, Gourab Banerjee ${ }^{3}$ \\ ${ }^{1}$ School of Mechanical Engineering, KIIT University, Bhubaneswar-751024 Odisha, India \\ ${ }^{2}$ Institute for Plasma Research, Bhat Village, Gandhinagar-382428 Gujarat, India \\ ${ }^{3}$ Department of Power Engineering, Jadavpur University, Kolkata, West Bengal, India
}

Corresponding Author Email: pcmishrafme@kiit.ac.in

https://doi.org/10.18280/ijht.360122

Received: 28 November 2017

Accepted: 2 February 2018

\section{Keywords:}

nanofluids, electronic cooling, microchannel, heatsink, optimization, EES

\begin{abstract}
This investigation intends to present a theoretical analysis, comparison and thermal optimization of a rectangular microchannel heat sink cooling by $\mathrm{TiO}_{2}$-water and $\mathrm{ZnO}$ Water nanofluids. Nanofluids at volume fractions of $1 \%, 2 \%, 4 \%, 6 \%, 8 \%$ and $10 \%$ are applied to evaluate and enhance the performance of the microchannel heat sinks. Engineering Equation Solver (EES) is used for optimizing the performance of heat sink. The inclusion of nanoparticles in the base fluid consequences to the reduction in thermal resistance with concurrent growth inthe pumping power. The reduction is thermal resistance is more intense for $\mathrm{ZnO}$-water nanofluids than $\mathrm{TiO}_{2}$-water nanofluids $\left(0.0000170 \mathrm{Km}^{2} \mathrm{~W}^{-1}\right.$ with $\mathrm{TiO}_{2}$-water and $0.0000136 \mathrm{Km}^{2} \mathrm{~W}^{-1}$ with $\mathrm{ZnO}$-water at $8 \%$ volume fraction). However, the pumping power needed for both the nanofluids at different volume fractions are found to be same $(0.53 \mathrm{~W}$ for both fluids at $8 \%$ volume fraction). The diminution of thermal resistance at same pumping power makes $\mathrm{ZnO}$-water nanofluids a potential candidate than $\mathrm{TiO}_{2}$-water nanofluids. Heat sink made with material of high thermal conductivity showed superior cooling performance. Additionally, for identical operative condition, both the nanofluids achieve quicker cooling performance than water. Consequently, nanofluids should be regarded as the future of the cooling agents for electronic cooling embarking excellence in the field of thermal optimization technology.
\end{abstract}

\section{INTRODUCTION}

The microchannel heat sink (MCHS) has become a new domain for researchers because of efficient heat transfer from small area in field of nanofluids thermal management [1]. The cooling system accommodates a number of parallel microchannels mounted on the top of the chip with an adiabatic cover to restrict the coolant within. The coolant takes away the heat as it runs through the channels. However, the swift growth in the power density with the miniaturization of modern electronic chips has expanded a substantial development in the research of cooling systems for MCHS. Areas of investigation encompass the materials, geometry, flow regimes etc. [2-12]. No new material has not been introduced still now, which can replace the standard copper and silicon that is used as the cover material for silicon chip at the base.

Air and water are mostly used as cooling agent due their availability and applicability at any flow conditions i.e. laminar or turbulent flow conditions. Air has low thermal transportability while water requires more pumping power and it can cause severe damage even if slight leakage occurs in the cooling system. The recent advancement in nanotechnology has helped us to produce nanofluids as an alternative cooling agent with superior cooling capacity. Nanofluids are made by dispersing nano-sized metallic and non-metallic particles in the basefluids like water, glycol etc.
The inclusion of nanoparticles in the base fluids augments the thermal conductivity of basefluids which results in higher heat transfer rate which has been communicated in the references [13-18]. Microchannel for electronic cooling were first proposed by Tuckerman and Pease[19]. They deployed circulation of water to cool MCHS which is made of silicon chips. The MCHS was capable of dissipating $7.9 \mathrm{MW} / \mathrm{m}^{2}$ when there was a $71{ }^{\circ} \mathrm{C}$ of temperature difference between substrate and inlet flow of water. However, the pressure drop across the channel length was quite large at $200 \mathrm{kPa}$ with plain MCHS and $380 \mathrm{kPa}$ with MCHS carrying pin-fins. Another crucial milestone was achieved by Philip[20], who analyzed the heat transfer and fluid flow inside MCHS and provided all the calculations for designing microchannel heat sinks. Lee and Mudawar [21] experimentally estimated the effectiveness of $\mathrm{Al}_{2} \mathrm{O}_{3}$-water nanofluids. They observed notable increase in overall heat transfer performance when it is utilized as single phase flow than double phase flow. They also proposed nanofluids as potential coolant for MCHS systems. Mohammad [22] chose numerical simulation of $\mathrm{Al}_{2} \mathrm{O}_{3}$-water nanofluids with $1 \%-5 \%$ volume fractions. They used finite volume scheme for modeling the performance of nanofluid flow laminar flow and found that rectangular MCHS showed lowest thermal resistance for nanofluids at 5\% particle volume fraction. Chein and Huang [1] performed an analytical study with different channel geometry and particle volume fractions. The overall performance of rectangular 
microchannel system was significantly boosted up with $\mathrm{Cu}$ Water nanofluids. A review of microchannels in terms of their fabrication and performance was provided by Kandlikar and Grande [23]. Li and Kleinstreuer [24] modelled trapezoidal MCHS cooled with $\mathrm{CuO}$-water nanofluids with entropy generation minimization method (EGM method) for nanofluids with $1 \%$ and $4 \%$ particle volume fractions under laminar flow. They presented an optimum range of Reynolds number suitable for heat transfer enhancement in heat sinks. Few years back, Ijam and Saidur [25] analyzed the overall performance of a rectangular minichannel which is cooled by $\mathrm{TiO}_{2}$-water and $\mathrm{SiC}$-water nanofluids flowing under turbulent regime. Nanofluids with $0.8 \%, 1.6 \%, 2.4 \%$, and $3.2 \%$ and $4 \%$ were used in their study. They reported thathigher heat transfer rate is achievable with $\mathrm{TiO}_{2}$-water nanofluids rather than SiC-water nanofluidsat identical particle volume fraction of $4 \%$. However, pumping power required at the same volume fractionwas moderately higher for $\mathrm{TiO}_{2}$-water nanofluids than SiC-water nanofluids. Escher et al.[26] derived a new correlation for Nusselt number from experimental data gathered by applying $\mathrm{SiO}_{2}$-water nanofluids with volume fraction of $5 \%, 16 \%$ and $31 \%$ respectively in rectangular MCHS.They reported that a better permanence could be accomplished with the increase of thermal capacity rather than increment in thermal conductivity. Shokouhmand et al. [27] studied the heat transfer performance of silicon microchannel heat sink flooded with $\mathrm{Cu}$-Water nanofluids flowing in both laminar and turbulent regions. They used artificial neural network (ANN) to simulate the heat sink under laminar flow condition and identified the appropriate geometry and volume fraction for thermal resistance minimization. Other important research on the optimization of nanofluids cooled MCHS can be found in the references [28-35].

In the previous paragraphs, the overall performance study of different nanofluids cooled heat sinks has been presented in brief. These studies mainly focus on the effect of volume fraction, geometric configuration and construction materials on the performance of cooling system for heat sinks. Different optimization schemes were deployed to measure the thermal performance of nanofluids cooled systems. Different oxide nanoparticles were considered for nanofluids. However, $\mathrm{TiO}_{2}$-water and $\mathrm{ZnO}$-water nanofluids are not used extensively. Optimization with engineering equation solver (EES) [36] has not been reported yet.

This present paper analyses and optimizes the thermal performance of rectangular microchannel heat sink cooling by $\mathrm{TiO}_{2}$-water and $\mathrm{ZnO}$-water nanofluids with engineering equation solver (EES), in which the existing models of thermal properties of coolants, thermal resistance and pressure drop are integrated. Thermal performance of the heat sink system is optimized with respect to the thermal conductivity, channel geometry and different heat sink materials at different nanofluids concentrations.

\section{THEORETICAL MODELING}

\subsection{The MCHS geometry}

A rectangular heat sink is regarded as the system of our present study is given in Fig. 1. The length of the heat sink $\left(\mathrm{L}_{\mathrm{hs}}\right)$ is $0.02 \mathrm{~m}$ and the channel height $\left(\mathrm{H}_{\mathrm{ch}}\right)$ is $300 \mu \mathrm{m}$. Width of the heat sink is $\left(\mathrm{W}_{\mathrm{hs}}\right) 0.01 \mathrm{~m}$. The substrate thickness $(\mathrm{t})$ is taken as $200 \mu \mathrm{m}$. The top surface is arrogated to be insulated. The bottom portion of the heat sink is exposed to constant heat flux (q) and an insulated plate is placed to cover the upper portion of heat sink. The geometrical specifications with working conditions are tabulated in Table1.

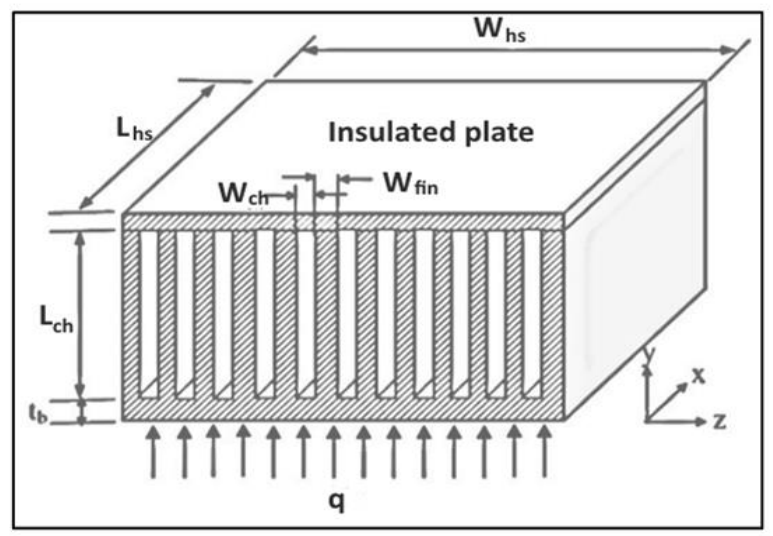

Figure 1. Schematic diagram of MCHS [27]

Table 1. Geometrical specifications and working conditions applied to this study

\begin{tabular}{ccc}
\hline Sl.No. & $\begin{array}{c}\text { Parameters/Operating } \\
\text { conditions }\end{array}$ & Values \\
\hline 1 & Heat sink length $\left(\mathrm{L}_{\mathrm{hs}}\right)$ & $0.02(\mathrm{~m})$ \\
2 & Channel height $\left(\mathrm{H}_{\mathrm{ch}}\right)$ & $300(\mu \mathrm{m})$ \\
3 & Width of the heat sink $\left(\mathrm{W}_{\mathrm{hs}}\right)$ & $0.01(\mathrm{~m})$ \\
4. & Substrate thickness $(\mathrm{t})$ & $200(\mu \mathrm{m})$ \\
5. & Flow rate $(\mathrm{v})$ & $4.7 \times 10^{-6}\left(\mathrm{~m}^{3} / \mathrm{s}\right)$ \\
\hline
\end{tabular}

\subsection{Modeling of thermo-physical properties of nanofluids}

$\mathrm{TiO}_{2}$-water and $\mathrm{ZnO}$-water nanofluids with $1 \%, 2 \%, 4 \%$, $6 \%, 8 \%$ and $10 \%$ volume fractions are engaged in the present study. The thermo-physical properties of these nanofluids are measured by mathematical correlations available in the previous literatures.

The density of nanofluids ( $\left.\rho_{\mathrm{nf}}\right)$ is taken as the average of the base fluid and particle densities $\left(\rho_{\mathrm{bf}}\right.$ and $\rho_{\mathrm{np}}$ ) based on the particle volume fraction $(\phi)$. The density of nanofluids is given by Boungiorno[37]:

$\rho_{\mathrm{nf}}=(1-\varphi) \rho_{\mathrm{bf}}+\varphi \rho_{\mathrm{np}}$

The specific heat of nanofluids $\left(\mathrm{c}_{\mathrm{nf}}\right)$ is calculated by using Boungiorno model[37]:

$c_{n f}=\frac{(1-\varphi) \rho_{b f} c_{b f}+\varphi \rho_{n p} c_{n p}}{\rho_{n f}}$

where, $c_{b f}$ and $c_{n p}$ are the specific heats of base fluid and nanoparticles respectively.

The thermal conductivity of nanofluids $\left(\mathrm{k}_{\mathrm{nf}}\right)$ are calculated using Hamilton-Crosser model [38]:

$\mathrm{k}_{\mathrm{nf}}=\left[\frac{\mathrm{k}_{\mathrm{np}}+(\mathrm{n}-1) \mathrm{k}_{\mathrm{bf}}-(\mathrm{n}-1) \varphi\left(\mathrm{k}_{\mathrm{bf}}-\mathrm{k}_{\mathrm{np}}\right)}{\mathrm{k}_{\mathrm{np}}+(\mathrm{n}-1) \mathrm{k}_{\mathrm{bf}}+\varphi\left(\mathrm{k}_{\mathrm{bf}}-\mathrm{k}_{\mathrm{np}}\right)}\right] \mathrm{k}_{\mathrm{bf}}$ 
where, $\mathrm{k}_{\mathrm{bf}}$ and $\mathrm{k}_{\mathrm{np}}$ are the thermal conductivities of basefluid and nanoparticles respectively.

In the above equation, $n$ is shape factor and the value of $n$ is 3 for as nanoparticles are considered here as spherical in shape.

The viscosity of nanofluids $\left(\mu_{\mathrm{nf}}\right)$ are calculated using Brinkman model [39]:

$\mu_{\mathrm{nf}}=\frac{\mu_{\mathrm{bf}}}{(1-\varphi)^{2.5}}$

where, $\mu_{\mathrm{bf}}$ denotes the viscosity of base fluid. Table 2 and Table3. show the thermo-physical properties of basefluid, nanoparticles and nanofluids at $30^{\circ} \mathrm{C}$.

Table 2. The thermo-physical characteristics of base fluid and nanoparticles

\begin{tabular}{|c|c|c|c|}
\hline Thermo-physical properties & $\mathrm{H}_{2} \mathrm{O}$ & $\mathrm{TiO}_{2}$ & $\mathrm{ZnO}$ \\
\hline Density $\left(\mathrm{kg} / \mathrm{m}^{3}\right)$ & 994.2 & 4157 & 5606 \\
\hline Specific heat $(\mathrm{J} / \mathrm{Kg} \cdot \mathrm{K})$ & 4178 & 710 & 4605 \\
\hline $\begin{array}{c}\text { Thermal } \\
\text { Conductivity }(\mathrm{W} / \mathrm{m} \cdot \mathrm{K})\end{array}$ & 0.625 & 8.4 & 21 \\
\hline Viscosity $\left(\mathrm{N} \cdot \mathrm{s} / \mathrm{m}^{2}\right)$ & $7.2 \times 10^{-4}$ & - & - \\
\hline
\end{tabular}

Table 3. Thermo-physical characteristics of $\mathrm{TiO}_{2}$-water and $\mathrm{ZnO}$-water nanofluids

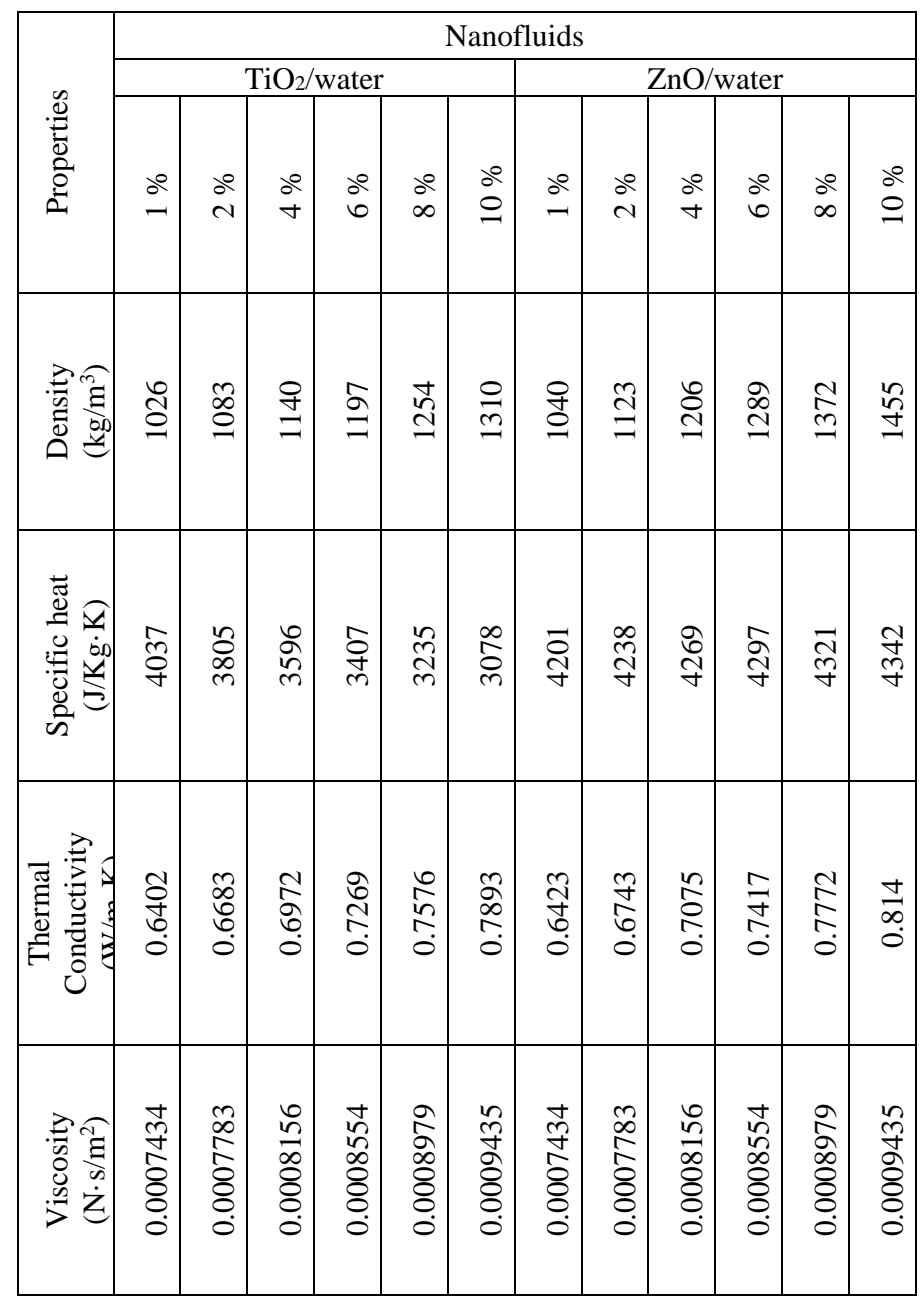

2.3 Thermal modeling of MCHS
Some assumptions are made to alleviate the following assumptions:

i. Flow is incompressible.

ii. Flow is considered to be steady and laminar.

iii. Thermophysical properties of the nanofluids are assumed to be constant.

iv. The inner walls of channels are smooth.

In this analysis, the thermal performance of heat sink is analyzed using the equation given below[10].

$\mathrm{R}_{\mathrm{th}}=\left(\frac{\mathrm{t}}{\mathrm{k}_{\mathrm{hs}}}\right)+\frac{\mathrm{L}_{\mathrm{hs}}}{\mathrm{c}_{\mathrm{nf}} \mu_{\mathrm{nf}}} \frac{2}{\operatorname{Re}}\left(\frac{1+\beta}{1+\alpha}\right)+\frac{1}{\mathrm{~h}_{\mathrm{avg}}}\left(\frac{1+\beta}{1+2 \alpha \eta}\right)$

where, $\mathrm{R}_{\mathrm{th}}$ is the thermal resistance of the MCHS, Re is Reynolds number, $\alpha=$ channel aspect ratio, $\beta=$ wall width to channel width, $h_{a v g}=$ average heat transfer coefficient, $\eta=$ fin efficiency, $k_{h s}$ is the thermal conductivity of heat sink materials.

The average heat transfer coefficient mentioned in equation(5) is evaluated using the correlation derived by Kim and $\mathrm{Kim}[40]$ for pure water flow through a rectangular heat sinks.

$$
h_{\text {avg }}=2.253+\left[8.164\left(\frac{\alpha}{\alpha+1}\right)^{1.5}\left(\frac{\mathrm{k}_{\mathrm{nf}}}{\mathrm{d}_{\mathrm{h}}}\right)\right]
$$

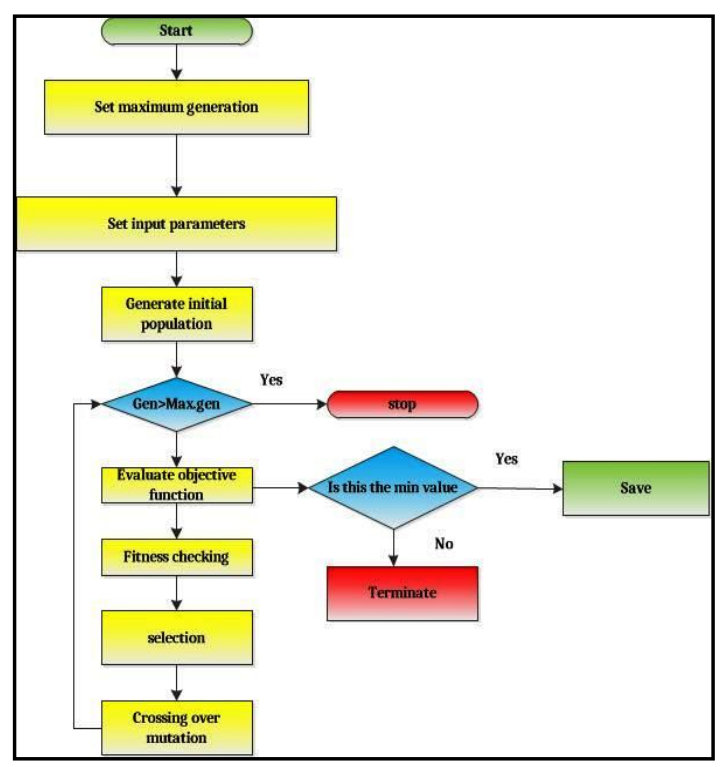

Figure 2. Flow chart of optimization process

The friction factor $f$ is calculated using the equation(7). Pumping power $\left(\mathrm{W}_{\mathrm{p}}\right)$ required to drive the coolant is calculated with the help of the equation(8).

$$
\begin{aligned}
& f \operatorname{Re}=4(4.7+19.64 \lambda) \\
& \text { where, } \lambda=\frac{(1 / \alpha)^{2}+1}{(1 / \alpha+1)^{2}}
\end{aligned}
$$


$\mathrm{w}_{\mathrm{p}}=\mathrm{v} \Delta \mathrm{p}=\mathrm{v}\left(\mathrm{f} \frac{\mathrm{L}_{\mathrm{hs}}}{\mathrm{d}_{\mathrm{h}}} \rho_{\mathrm{nf}} \frac{\mathrm{u}_{\mathrm{nf}}^{2}}{2}\right)$

where, $\Delta \mathrm{p}$ is pressure drop across microchannel.

\section{OPTIMIZATION PROCEDURE}

The optimization process has been done in Engineering Equation Solver (EES) software. It contains inbuilt optimization module. The module contains different optimization procedures out of which genetic optimization method has been adopted.In this analysis, the present system is considered to be a multi-objective function system with two objective functions associated with the evaluation of thermo-fluidic performances. Thermal resistance and pumping power are considered here as the objective functions. EES uses its inbuilt genetic optimization module to minimize thermal resistance and pumping power simultaneously for the values of different parameters like particle volume fraction, design parameters etc. The values of design parameters $(\alpha$ and $\beta$ ) are collected from the reference [41]. The limits of design parameters are tabulated in Table4.The flowchart of the whole optimization process is illustrated in the Fig. 2.

Table 4. Limits of design parameters $(\alpha, \beta)$

\begin{tabular}{|c|c|c|}
\hline \multirow{2}{*}{$\begin{array}{c}\text { Design } \\
\text { parameter }\end{array}$} & \multicolumn{2}{|c|}{ limits } \\
\cline { 2 - 3 } & Upper & Lower \\
\hline$\alpha$ & 10 & 1 \\
\hline$\beta$ & 0.1 & 0.01 \\
\hline
\end{tabular}

\section{RESULTS AND DISCUSSION}

\subsection{Influence of nanofluids concentration}

The effect of particle volume fraction on the thermal resistance and pumping power is observed for $1 \%, 2 \%, 4 \%$, $6 \%, 8 \%$ and $10 \%$ volume fractions for both $\mathrm{TiO}_{2}$-water and $\mathrm{ZnO}$-water nanofluids. Figure 3. shows the effect of particle volume fraction on thermal resistance. The thermal resistance shows a declining trend with the nanoparticle inclusion in base fluids. Several studies [25, 42, 43] show that addition of nanoparticles increases thermal conductivity of nanofluids. From equation (5), it is observed that increase in thermal conductivity helps to decrease convective thermal resistance by increasing the convective heat transfer rate during nanofluids flow. The drop in thermal resistance is more in $\mathrm{ZnO}$-water nanofluids than $\mathrm{TiO}_{2}$-water nanofluids. The lowest thermal resistance is found at $10 \%$ volume fraction for both kinds of nanofluids.

Figure 4.shows the linear growth of pumping power with the increase in particle volume fraction for all kinds of nanofluids. The pumping power is influenced by the accumulated values of the viscosity and density of nanofluids. Due to higher density and viscosity of nanofluids, required pumping power goes on increasing with nanofluids concentration. In this present study, the increment of pumping power is same for both kinds of nanofluids.

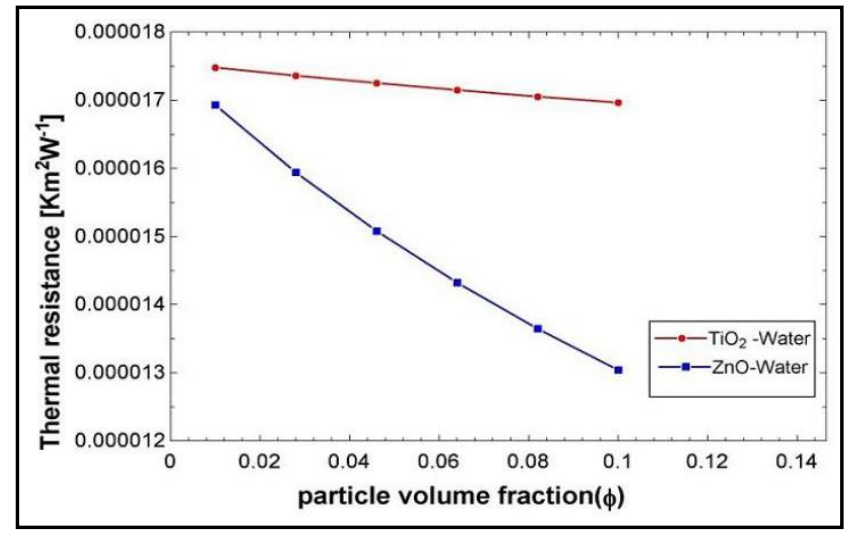

Figure 3. Effect of nanofluid concentration on thermal resistance

According to mathematical model, viscosity enhancement of nanofluid is function of volume fraction. Additionally, the flow condition i.e. flow rate, flow velocity, geometric configuration and for heat sinks are considered identicalduring the application of each nanofluids. The inner wall of the microchannel heat sinks is also assumed to be smooth during analysis. Due to which both kinds nanofluids show same pumping power enhancement with particle volume fraction increment. Wu et al. [44] reported same pumping power enhancement with flow velocity shown by different nanofluids when flows through same microchannels and same substrate material is used.

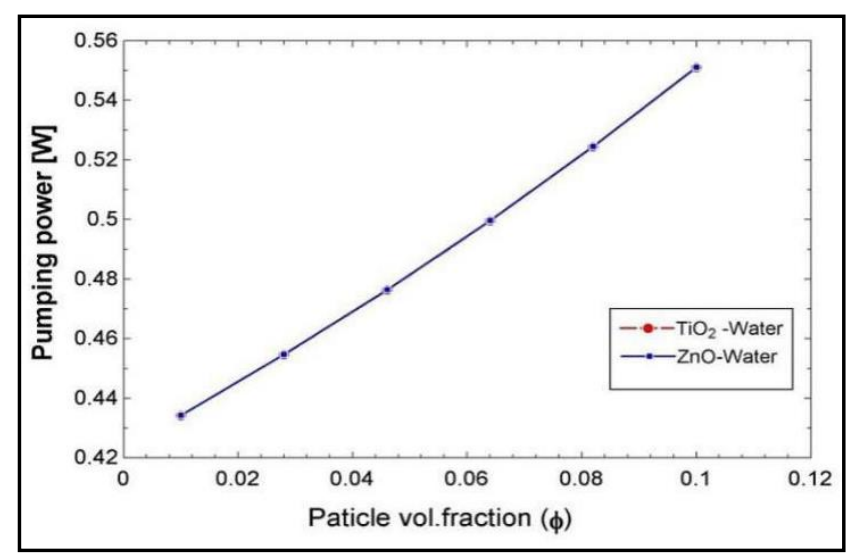

Figure 4. Effect of nanofluid concentration on pumping power

\subsection{Influence of the geometry of MCHS}

Figure 5. shows the effect of channel aspect ratio $(\alpha)$ on thermal resistance at $8 \%$ volume fraction. Alteration of aspect ratio $(\alpha)$ influences the thermal resistance and pumping power. The channel height remains constant during the optimization process while the channel width decreases. Narrowing channel width boosts convective heat transfer rate from channel wall that diminishes convective thermal resistance and overall thermal resistance decreases consequently.

It is well known fact that narrowing of channels demand additional pumping power to circulate cooling agent. Figure6. which depicts the relationship between pumping power and aspect ratio at particle volume fraction of $8 \%$ delivers the evidence. Here, the behavior of the graph is same for both 
nanofluids as the other parameters are remains constant. Halefadl et al.[30] also observed decrease in thermal resistance and increase in pumping power with the increase of $\alpha$ within the prescribed range while investigating micro channel heat sinks with carbon nanotube-water nanofluids.

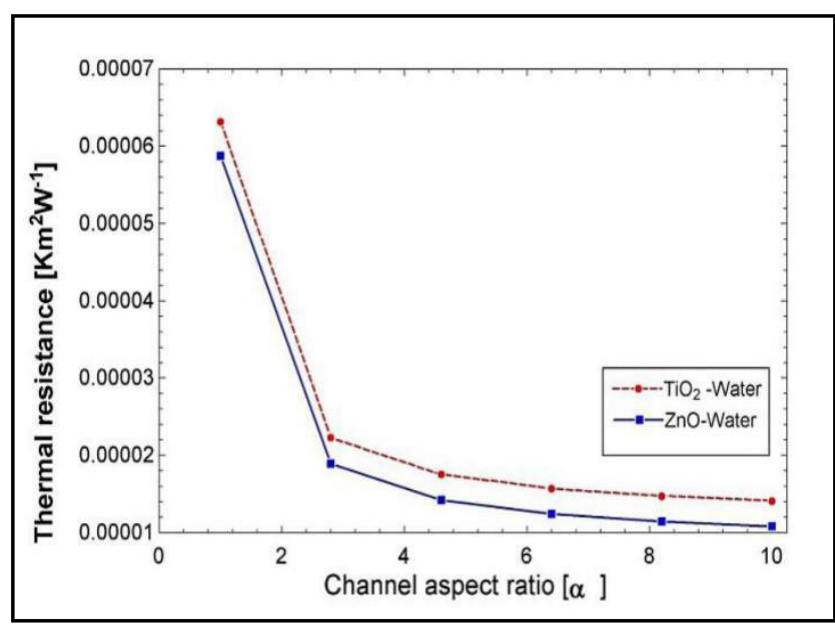

Figure 5. Variation of thermal resistance with $\alpha$.

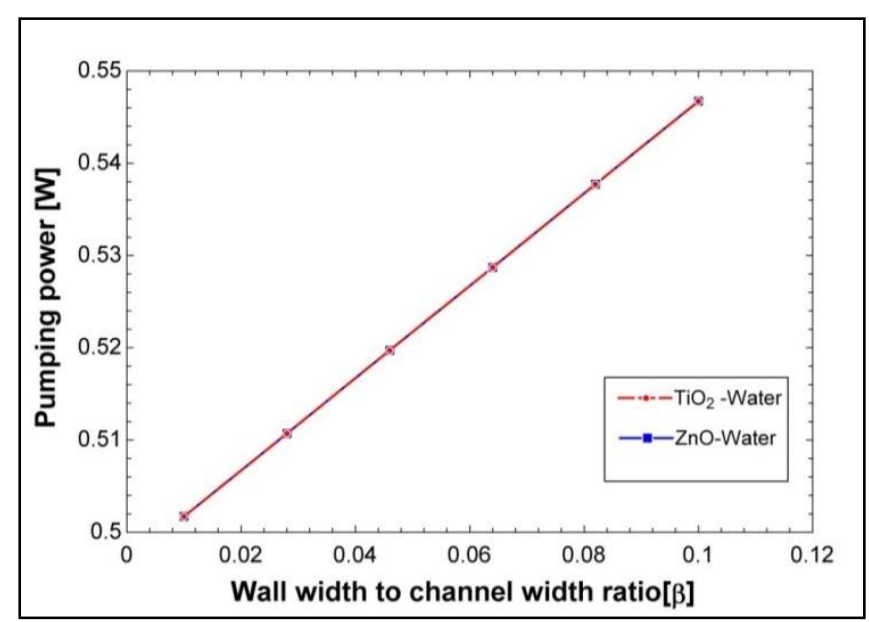

Figure 6. Variation of pumping power with $\alpha$

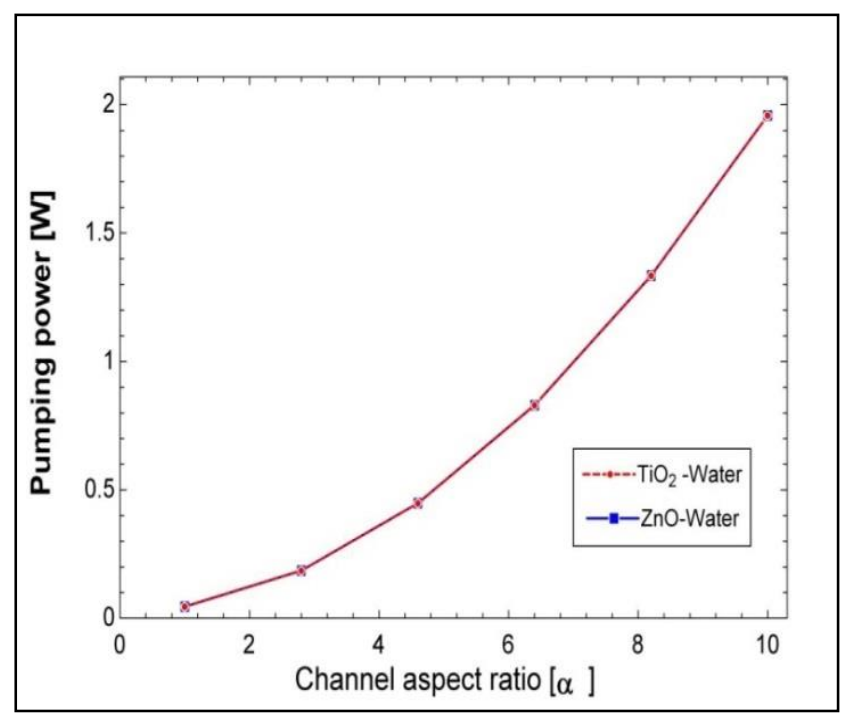

Figure 7. Variation of thermal resistance with $\beta$
Figure 7. and Figure 8. display the effect of the ratio of wall width to channel width $(\beta)$ on the thermal resistance and pumping power at $8 \%$ of particle volume fraction. Increase in the value of $\beta$ leads to a drop in thermal resistance and an increase in pumping power. For a particular value of wall width, the increment is attributed to the reduction in the width of microchannel.The present behavior confirms the trend identified when the effect of aspect ratio $(\alpha)$ is investigated. The performance of MCHS is more responsive to $\alpha$ than $\beta$. Adham et al. [41] applied aqueous $\mathrm{TiO}_{2}$ and $\mathrm{SiC}$ nanofluids to a rectangular heat sink and observed same behavior of thermal resistance and pumping power when they increase the value of $\beta$ with in the range of $0.01-0.1$.

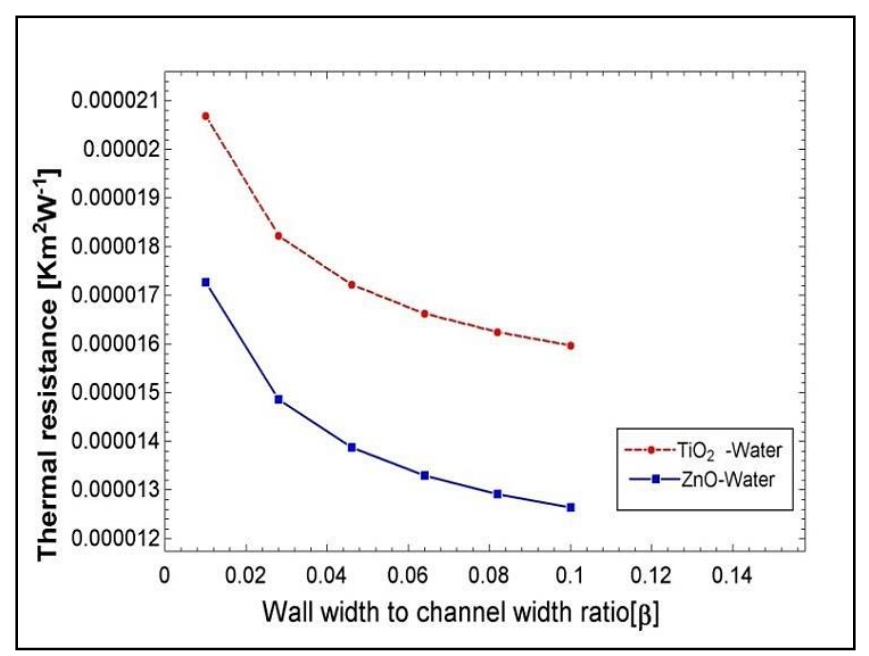

Figure 8. Variation of pumping power with $\beta$

\subsection{Influence of fabrication material}

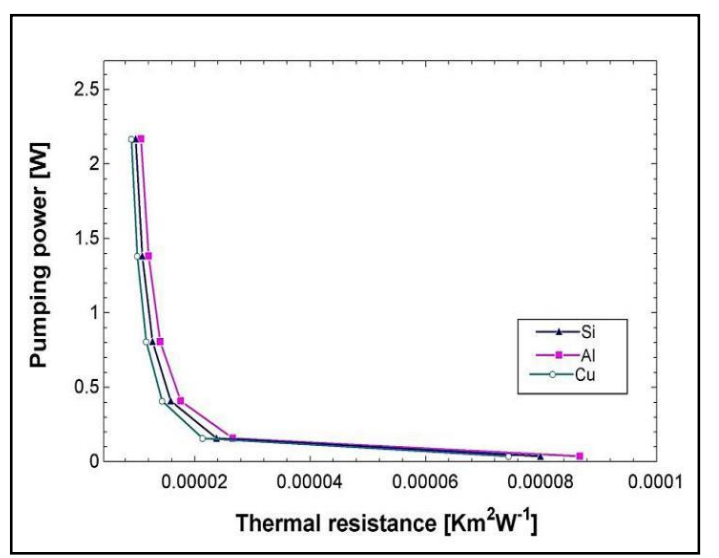

Figure 9. Variation of system performance with different heat sink materials when $\mathrm{TiO}_{2}$-water nanofluid is applied

Thermal properties of fabrication material alter the performance of heat sinks. MCHS's of same geometric configuration, made with different material when flooded with the same type of nanofluids will show a variety of thermal resistance values. Figures 9. and figure 10. compare the performance of MCHS's made with Silicon, Aluminum and Copper using both types of nanofluids. It is evident from equation 5 . that if the thermal conductivity of fabrication material of heat sinks is increased then there will be a significant decrease in thermal resistance. Copper made microchannels shows better performance than silicon and 
aluminum since copper has highest thermal conductivity among them.

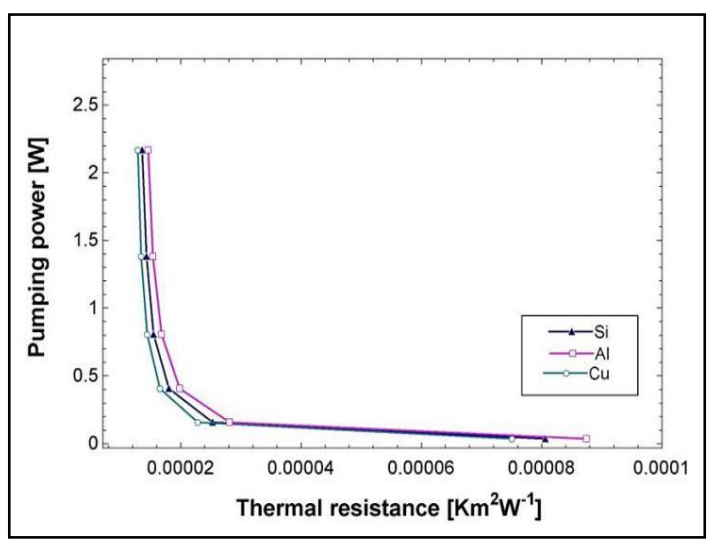

Figure 10. Variation of system performance with different heat sink materials whenZnO -water nanofluid is applied

High thermal conductivity value helps to increase the overall thermal performance by reducing conductive thermal resistance significantly through the substrate side. Therefore, material with higher thermal conductivity is suitable for fabricating the

MCHS's.In similar operating condition, Copper made heat sinks provides the lower thermal resistance $\left(1.29 \times 10^{-5}\right.$ $\mathrm{Km}^{2} \mathrm{~W}^{-1}$ with $\mathrm{TiO}_{2}$-water and $0.947 \times 10^{-5} \mathrm{Km}^{2} \mathrm{~W}^{-1}$ with $\mathrm{ZnO}$ water) than aluminum $\left(1.359 \times 10^{-5} \mathrm{Km}^{2} \mathrm{~W}^{-1}\right.$ with $\mathrm{TiO}_{2}$-water and $1.032 \times 10^{-5} \mathrm{Km}^{2} \mathrm{~W}^{-1}$ with $\mathrm{ZnO}$-water), silicon $\left(1.445 \times 10^{-5}\right.$ $\mathrm{Km}^{2} \mathrm{~W}^{-1}$ with $\mathrm{TiO}_{2}$-water and $1.17 \times 10^{-5} \mathrm{Km}^{2} \mathrm{~W}^{-1}$ with $\mathrm{ZnO}$ water). Table 5 . shows the optimized results of various parameters for different structural materials.

Table 5. Optimized values of the present study for different heat sink materials

\begin{tabular}{|c|c|c|c|c|}
\hline \multirow{4}{*}{$\begin{array}{c}\text { Nanofluid } \\
\text { Type }\end{array}$} & $\begin{array}{c}\text { Optimized } \\
\text { Parameters }\end{array}$ & \multicolumn{3}{|c|}{ Materials } \\
\cline { 2 - 5 } & $\begin{array}{c}\mathrm{R}_{\mathrm{th}} \\
\left(\mathrm{Km}^{2} \mathrm{~W}^{-1}\right)\end{array}$ & $1.445 \times 10^{-5}$ & $1.359 \times 10^{-5}$ & $1.29 \times 10^{-5}$ \\
\cline { 2 - 5 } $\mathrm{TiO}_{2}$-Water & $\mathrm{Wp}(\mathrm{W})$ & 2.2 & 2.1 & 1.928 \\
\cline { 2 - 5 } & $\alpha$ & 9.98 & 9.98 & 9.97 \\
\cline { 2 - 5 } & $\beta$ & 0.1 & 0.1 & 0.1 \\
\hline \multirow{4}{*}{ ZnO-Water } & $\begin{array}{c}\mathrm{R}_{\mathrm{th}} \\
\left(\mathrm{Km} 2 \mathrm{~W}-{ }^{1}\right)\end{array}$ & $1.17 \times 10^{-5}$ & $1.032 \times 10^{-5}$ & $0.947 \times 10^{-5}$ \\
\cline { 2 - 5 } & $\mathrm{Wp}(\mathrm{W})$ & 2.1 & 1.928 & 1.927 \\
\cline { 2 - 5 } & $\alpha$ & 9.99 & 9.96 & 10 \\
\cline { 2 - 5 } & $\beta$ & 0.1 & 0.1 & 0.11 \\
\hline
\end{tabular}

\section{CONCLUSION}

Microchannel heat sinks cooling with nanofluids are expected to meet the constantly increasing demand of heat flux removal from modern generation electronic equipment. In this present investigation, the thermal performance of MCHS is analyzed and optimized. Two different types of nanofluids namely $\mathrm{TiO}_{2}$-water and $\mathrm{ZnO}$-water nanofluids are deployed as coolants for the system. The following conclusions are drawn.

1) Nanofluids having higher thermal conductivity and slightly higher viscosity than base fluids are promising as coolants for MCHS's. This indicates towards further theoretical and experimental studies expected to happen in near future to find the better combinations of nanoparticles and base fluids for effective utilization of nanofluids.

2) The thermal resistance is greatly influenced by the variation of nanofluids concentration. Use of nanofluids reduces the thermal resistance. More the concentration of nanofluids less is the thermal resistant of MCHS's. Nanofluids in combination with substrate material of higher thermal conductivity cause extra reduction in thermal resistance.

3) Application of nanofluids increases pumping power. The pumping power increases with particle vol. fraction. $\mathrm{TiO}_{2}$-water and $\mathrm{ZnO}$-water nanofluids both require same pumping power under same flow condition and geometric configuration of heat sinks. To save power consumption due to pumping, less viscous nanofluids are recommended as coolants.

4) Performance of MCHS's is more sensitive to the variation of aspect ratio $(\alpha)$ than wall width to channel width ratio $(\beta)$. Therefore, a rigorous investigation is required for proper design of microchannel heat sink.

5) The implementation of $\mathrm{ZnO}$-water nanofluids is better than the $\mathrm{TiO}_{2}$-water nanofluids since least thermal resistance is achievable with $\mathrm{ZnO}$-water nanofluids at same pumping power.

The improvement of heat transfer is indicated by the decrease in thermal resistance with the application of nanofluids as coolant. The increased pumping power reduces the performance of heat sinks. The $\mathrm{ZnO}$-water nanofluids show better performance than $\mathrm{TiO}_{2}$-water nanofluids at identical pumping power requirement provided under same flow condition and identical geometry of heat sinks. Moreover,MCHS made with materials of higher thermal conductivity shows minimum thermal resistance. Therefore, it is suggested that future investigation should be conducted with heat sinks made with materials having high thermal conductivity and nanofluids with low concentration nanoparticles. This would give superior thermal performance at relatively low pumping power.

\section{REFERENCES}

[1] Chein R, Huang G. (2005). Analysis of microchannel heat sink performance using nanofluids. Applied Thermal Engineering 25(17): 3104-3114.

[2] Hetsroni G. et al. (2004). Drag reduction and heat transfer of surfactants flowing in a capillary tube. International Journal of Heat and Mass Transfer. 47(17): 3797-3809.

[3] Tiselj I, et al. (2004). Effect of axial conduction on the heat transfer in micro-channels. International Journal of Heat and Mass Transfer 47(12): 2551-2565.

[4] McHale JP, Garimella SV. (2010). Heat transfer in trapezoidal microchannels of various aspect ratios. International Journal of Heat and Mass Transfer 53(1): 365-375.

[5] Perret C, Schaeffer C, Boussey J. (1998). Microchannel integrated heat sinks in silicon technology. in Conference Record of 1998 IEEE Industry Applications Conference. Thirty-Third IAS Annual Meeting (Cat. No.98CH36242).

[6] Hetsroni G, et al. (2005). Heat transfer in microchannels: Comparison of experiments with theory and 
numerical results. International Journal of Heat and Mass Transfer 48(25): 5580-5601.

[7] Khan WA, Culham JR, Yovanovich MM. (2009). Optimization of microchannel heat sinks using entropy generation minimization method. IEEE Transactions on Components and Packaging Technologies 32(2): 243251.

[8] Liu D, Garimella S.V. (2005). Analysis and optimization of the thermal performance of microchannel heat sinks. International Journal of Numerical Methods for Heat \& Fluid Flow 15(1): 7-26.

[9] Liu KV, et al. (1988). Measurements of pressure drop and heat transfer in turbulent pipe flows of particulate slurries.

http://digital.library.unt.edu/ark:/67531/metadc282865/.

[10] Adham AM, Mohd-Ghazali N, Ahmad R. (2012). Optimization of an ammonia-cooled rectangular microchannel heat sink using multi-objective nondominated sorting genetic algorithm (NSGA2). Heat and Mass Transfer 48(10): 1723-1733.

[11] Mohammed Adham A, Mohd-Ghazali N., Ahmad R. (2013). Thermal and hydrodynamic analysis of microchannel heat sinks: A review. Renewable and Sustainable Energy Reviews 21: 614-622.

[12] Kosar A. (2010). Effect of substrate thickness and material on heat transfer in microchannel heat sinks. International Journal of Thermal Sciences 49(4 SRC GoogleScholar): 635-642.

[13] Cherkasova A., Shan J. (2006). Thermal conductivity enhancement of nanofluids, in Carbon Nanotubes, V.N. Popov and P. Lambin, Editors. Springer, Dordrecht, 235-236.

[14] Das SK. et al. (2003) Temperature dependence of thermal conductivity enhancement for nanofluids. Journal of Heat Transfer 125(4): 567-574.

[15] Hwang YJ, et al. (2006). Investigation on characteristics of thermal conductivity enhancement of nanofluids. Current Applied Physics 6(6): 1068-1071.

[16] Murshed SMS, Leong KC, Yang C. (2005). Enhanced thermal conductivity of $\mathrm{TiO}_{2}$-water based nanofluids. International Journal of Thermal Sciences 44(4): 367373.

[17] Saidur R, Leong KY, Mohammad HA. (2011). A review on applications and challenges of nanofluids. Renewable and Sustainable Energy Reviews 15(3): 1646-1668.

[18] Tawfik MM. (2017). Experimental studies of nanofluid thermal conductivity enhancement and applications: A review. Renewable and Sustainable Energy Reviews 75: 1239-1253.

[19] Tuckerman DB., Pease RFW. (1981). High-performance heat sinking for VLSI. IEEE Electron Device Letters 2(5): 126-129.

[20] Phillips RJ. (1988). Microchannel heat sinks. Lincoln Lab. J. 1(1): 31-48.

[21] Lee J., Mudawar I. (2007) Assessment of the effectiveness of nanofluids for single-phase and twophase heat transfer in micro-channels. International Journal of Heat and Mass Transfer 50(3): 452-463.

[22] Mohammed HA, Gunnasegaran P, Shuaib NH. (2010). Heat transfer in rectangular microchannels heat sink using nanofluids. International Communications in Heat and Mass Transfer 37(10): 1496-1503.

[23] Kandlikar SG, Grande WJ. (2003). Evolution of microchannel flow passages--thermohydraulic performance and fabrication technology. Heat Transfer Engineering 24(1): 3-17.

[24] Li J, Kleinstreuer C. (2010). Entropy generation analysis for nanofluid flow in microchannels. Journal of Heat Transfer 132(12): 122401-122401-8.

[25] Ijam A, Saidur R. (2012). Nanofluid as a coolant for electronic devices (cooling of electronic devices). Applied Thermal Engineering 32: 76-82.

[26] Escher W. et al. (year). On the cooling of electronics with nanofluids. Journal of Heat Transfer 133(5): 051401-051401-11.

[27] Shokouhmand H, Ghazvini M, Shabanian J. (2008). Performance analysis of using nanofluids in microchannel heat sink in different flow regimes and its simulation using artificial neural network in Proceedings of the World Congress on Engineering WCE.

[28] Adham AM, Mohd-Ghazali N, Ahmad R. (year). Cooling of microchannel heat sinks with gaseous coolants, Procedia Engineering 56: 337-343.

[29] Adham AM, Mohd-Ghazali N, Ahmad R. (2016). Optimization of nanofluid-cooled microchannel heat sink. Thermal Science. 20(1): 109-118.

[30] Halelfadl S, et al. (2014). Optimization of thermal performances and pressure drop of rectangular microchannel heat sink using aqueous carbon nanotubes based nanofluid. Applied Thermal Engineering 62(2): 492-499.

[31] Leng C, et al. (2015). Multi-parameter optimization of flow and heat transfer for a novel double-layered microchannel heat sink. International Journal of Heat and Mass Transfer 84: 359-369.

[32] Pourmehran O, et al. (2015). Numerical optimization of microchannel heat sink (MCHS) performance cooled by KKL based nanofluids in saturated porous medium. Journal of the Taiwan Institute of Chemical Engineers 55: 49-68.

[33] Rahimi-Gorji M, et al. (2015). Statistical optimization of microchannel heat sink (MCHS) geometry cooled by different nanofluids using RSM analysis. The European Physical Journal Plus 130(2): 22.

[34] Sakanova A, et al. (2014). Optimization and comparison of double-layer and double-side micro-channel heat sinks with nanofluid for power electronics cooling. Applied Thermal Engineering 65(1): 124-134.

[35] Wang XD, et al. (2013). Inverse geometric optimization for geometry of nanofluid-cooled microchannel heat sink. Applied Thermal Engineering 55(1): 87-94.

[36] Klein SA, Alvarado FL. (2002). Engineering Equation Solver. F-Chart Software.

[37] Buongiorno J. (2005). Convective Transport in Nanofluids. Journal of Heat Transfer 128(3 SRC Google Scholar): 240-250.

[38] Hamilton RL, Crosser OK. (1962). Thermal conductivity of heterogeneous two-component systems. Industrial \& Engineering Chemistry Fundamentals 1(3): 187-191.

[39] Brinkman HC. (1952). The viscosity of concentrated suspensions and solutions. The Journal of Chemical Physics 20(4): 571-571.

[40] Kim SJ, Kim D. (1992). Forced cooling. Journal of Heat Transfer 121(3): 639-645.

[41] Adham AM, Mohd-Ghazali N, Ahmad R. (2016). 
Optimization of nanofluid cooled microchannel heat sink. Thermal Science 20(1): 109-118.

[42] Townsend J. Christianson RJ. (2009). Nanofluid properties and their effects on convective heat transfer in an electronics cooling application. ASME J Thermal Sci Eng Appl 9 doi10111514001123. 1(3 SRC GoogleScholar): 031006-031006.

[43] Kumar N, Singh D. (2015). Analysis of thermal resistance and pumping power of rectangle micro channel heat sink for upper flow with different coolant. Global Journal of Research In Engineering.

[44] Wu JM, Zhao JY, July O. (2014). Conjugated numerical study on the performance of microchannel heat sink using $\mathrm{Al}_{2} \mathrm{O}_{3} / \mathrm{H}_{2} \mathrm{O}$. In 22nd International Conference on Nuclear Engineering (pp. V004T1T10A049). American Society of Mechanical Engineers. SRC - Google Scholar: 0A049-V004.

\section{NOMENCLATURE}

$\mathrm{c}=$ specific heat, $(\mathrm{J} / \mathrm{Kg} \cdot \mathrm{K})$

$\mathrm{d}_{\mathrm{h}}=$ hydraulic diameter of the fluid flow, $(\mathrm{m})$

$f=$ friction factor

$\mathrm{h}_{\mathrm{avg}}=$ average heat transfer coefficient, $\left(\mathrm{W} / \mathrm{m}^{2} \mathrm{~K}\right)$

$\mathrm{H}_{\mathrm{ch}}=$ Channel height, $(\mu \mathrm{m})$

$\mathrm{k}=$ thermal conductivity, $(\mathrm{W} / \mathrm{m} \cdot \mathrm{K})$
$\mathrm{L}_{\mathrm{hs}}=$ heat sink length,(m)

$\mathrm{n}=$ shape factor of nanoparticles

$\mathrm{p}=$ pumping pressure $(\mathrm{Pa})$

$\mathrm{Re}=$ Reynolds number

$\mathrm{R}_{\mathrm{th}}=$ thermal resistance of heat sinks, $\left(\mathrm{Km}^{2} / \mathrm{W}\right)$

$\mathrm{t}=$ substrate thickness, $(\mathrm{m})$

$\mathrm{u}=$ velocity, $(\mathrm{m} / \mathrm{s})$

$\mathrm{v}=$ flow rate, $\left(\mathrm{m}^{3} / \mathrm{s}\right)$

$\mathrm{W}_{\mathrm{hs}}=$ width of heat sink, $(\mu \mathrm{m})$

$\mathrm{W}_{\mathrm{p}}=$ pumping power, $(\mathrm{W})$

\section{Greek symbols}

$\alpha$, aspect ratio

$\beta$, wall width to channel width ratio

$\lambda$, geometrical factor of microchannel

$\Delta$, change

$\rho$, density $\left(\mathrm{kg} / \mathrm{m}^{3}\right)$

$\mu$, dynamic viscosity $\left(\mathrm{N} \cdot \mathrm{s} / \mathrm{m}^{2}\right)$

$\eta$, fin efficiency

$\phi$, nanoparticle volume fraction

\section{Subscript}

bf, base fluids

$\mathrm{np}$, nanoparticle

nf, nanofluid 